\title{
Assessment of Blasting-Induced Ground Vibration in an Open-Pit Mine under Different Rock Properties
}

\author{
Zhi-qiang Yin $\mathbb{D}^{1},{ }^{1,2}$ Zu-xiang Hu $\mathbb{D}^{1},{ }^{1}$ Ze-di Wei, ${ }^{1}$ Guang-ming Zhao, ${ }^{1}$ Ma Hai-feng, \\ Zhuo Zhang, ${ }^{1}$ and Rui-min Feng ${ }^{3}$ \\ ${ }^{1}$ School of Mining and Safety, Anhui University of Science and Technology, Huainan 232001, Anhui, China \\ ${ }^{2}$ School of Civil and Mechanical Engineering, Curtin University, Perth 6102, Western Australia, Australia \\ ${ }^{3}$ Department of Chemical and Petroleum Engineering, University of Calgary, Calgary, Canada T2N 1N4
}

Correspondence should be addressed to Zu-xiang Hu; zxhu@aust.edu.cn

Received 19 April 2018; Accepted 29 August 2018; Published 25 October 2018

Academic Editor: Xiang Fan

Copyright $(92018$ Zhi-qiang Yin et al. This is an open access article distributed under the Creative Commons Attribution License, which permits unrestricted use, distribution, and reproduction in any medium, provided the original work is properly cited.

In an open-pit mine slope, rock mass has multiple joint structures and blasting operations have an obvious influence on its stability. Therefore, accurately predicting the blasting vibration is necessary to ensure slope stability. In this study, the blasting vibration signals monitored at a blasting site with different rock masses were used to investigate the attenuation characteristics of blasting vibration through the peak particle velocity (PPV), frequency characteristics, and energy distribution of the blasting vibration signals analyzed with the time-frequency processing method. The results demonstrated that the main vibration frequency of the blasting vibration of dolomite was wider than that of shale, and these main vibration frequencies occurred at $25 \mathrm{kHz}$ and $14 \mathrm{kHz}$ for dolomite and shale, respectively, at a distance of $50 \mathrm{~m}$ from the blast area to the vibration monitoring point. With an increase in the distance from $50 \mathrm{~m}$ to $200 \mathrm{~m}$, the main vibration frequencies decreased to less than $5 \mathrm{~Hz}$. With increasing joint degree, the attenuation rate of the vibration velocity and energy attenuation of the blasting vibration increase, indicating that the structural parameters of the rock mass (such as the number of joints) have a significant impact on the attenuation law of blasting vibration. Furthermore, a modified equation that can be used for predicting PPV was developed by considering the effect of the number of joints in the rock mass on the blasting vibration. For the same ground vibration readings, the correlation factor increased from 0.8 to 0.85 for the Nicholls-USBM equation and the modified equation, respectively. The PPV of blasting under different rock masses of the Baideng open-pit phosphorite mine was used to verify the modified equation. The results show that a modified equation can be used for predicting the PPV of blasting engineering in the Baideng phosphorite mine and that the prediction accuracy is acceptable.

\section{Introduction}

The primary operation in open-pit mines is rock blasting. In blasting, only $20 \%-30 \%$ of the energy produced by the explosives is converted into mechanical energy to fragment and displace the rock mass. The remainder of the explosive energy is wasted in the form of blast disturbances, such as rock vibrations, noise, and fly rock, among others. Rock masses are typically characterized by discontinuous and anisotropic inhomogeneous structures. These discontinuous structures, such as faults, joints, fissures, and fractured zones, are randomly distributed in the rock mass and have important implications for blasting engineering. In blasting operations, natural cracks in the rock mass structure are changed by additional stresses induced by the blasting, and the shear strength of the structural surface is significantly reduced, thereby decreasing the stability of the rock $[1,2]$. Studies on blast vibration harm control are conducted based on analysis of blast vibrations. Peak particle velocity (PPV) is an evaluation criterion for the blasting vibration which has been used for many years; it is predicted by the distance and the charge weight scaling law $[3,4]$. In recent years, many researchers have conducted studies on the mechanical properties and strength of structural planes $[5,6]$ and their 
influence on the slope stability of the surface structure of rock masses [7-11]. However, only a few studies have been carried out regarding the vibration wave propagation characteristics of structural planes. Studies on the vibration effects of blasting have described the transmission and reflection of the stress wave on the surface of the structure using theoretical analysis and have focused primarily on the amplitude attenuation effect of structures on the stress wave [12-14]. Therefore, research on the effect of rock mass media on the attenuation of blasting vibration and accurate analysis of the influence of rock structures on the propagation of vibration attenuation in blasting engineering is worth further investigation.

Over the last several decades, additional sophisticated approaches, such as the finite element method and artificial neural networks, have been used to predict blast vibration [15-17]. Many researchers have successfully attempted to process and analyze unstable random blast vibration signals using signal time-frequency analysis [18-20]. Studies have also explored the influence of the distance from the blasting center on the frequency band energy distribution of blast vibration signals, and signal time-frequency analysis has become an effective method for investigating the energy distribution characteristics of a blast vibration signal under rock mass joints. Based on the results for the time-frequency characteristics of blasting signals, research on factors influencing blasting vibration, establishment of a regression formula describing blasting vibration, and analysis of signal time-frequency are effective and important methods for the study of blasting vibration hazards.

In this study, ground vibration monitoring data were obtained from the Baideng open-pit phosphorite mine in China. The energy spectrum of the blast vibration signal obtained from the measurement data collected during blasting was then analyzed using a time-frequency analysis method. The influence of the rock mass structure on the attenuation of blast seismic waves was explored from the perspective of the blast vibration energy. Finally, these vibration monitoring data were used to develop a new relationship, in which the influence of discontinuous structures is included in the number of joints in rock masses. The PPV for different rock masses was used to verify this relationship.

\section{Materials and Methods}

2.1. General Project Site Information. This study was conducted at the Baideng open-pit phosphorite mine, which is a subsidiary of the Guangming Chemical Co., Ltd. This mine is located in Anning, Yunnan, China. The Baideng open-pit phosphorite mine lies at a latitude of $24^{\circ} 52^{\prime} \mathrm{N}$ and a longitude of $102^{\circ} 22^{\prime} \mathrm{E}$. The dip of the strata is gently inclined and varies from $8^{\circ}$ to $20^{\circ}$. The strata overlying the ore body are dolomite, shale, and quaternary eluvial alluvium. Deep-hole bench blasting at a height of $10 \mathrm{~m}$ is used in this mine, as illustrated in Figures 1 and 2. In the mining area, blasting excavation has been used in dolomite and shale, and these rock strata have developed fault joints. Mechanical parameters of the intact rock masses such as the uniaxial compressive strength and tensile strength were tested according to the methods recommended by the International Society of Rock Mechanics (ISRM) [21-24]. The rock mass wave velocity and the number of joints were also measured [25]. The mechanical properties of the intact rock masses are summarized in Table 1.

Ammonium nitrate-fuel oil (ANFO) and nonelectric detonators were used for the blasting excavation. The typical depth and diameter of the blast holes were $11 \mathrm{~m}$ and $130 \mathrm{~mm}$, respectively, resulting in a blasting pattern with a burden of $4 \mathrm{~m}$ and spacing of $5 \mathrm{~m}$. In-hole delay detonators operated at $400 \mathrm{~ms}$. An initiation pattern was produced on the surface using NONEL with a delay of $25 \mathrm{~ms}$. An example of the initiation network and pattern of drilling holes is shown in Figure 3.

2.2. PPV Monitoring and Prediction Methods. The vibration monitoring points and blasting area were located at the same elevation. The distances between the monitoring points and blasting area were 50,100,150, and $200 \mathrm{~m}$, as shown in Figure 4. A blasting vibration recorder (EXP 3850) and a sensor (CDJ-1) were used to monitor blasting vibrations. Each monitoring point was equipped with a vibration sensor. The sensor must be bonded to the surface of the intact rock with plaster, and the location of the monitoring points must be adjusted appropriately to ensure the accuracy of the measurements. Thus, the distance and azimuth were determined using GPS, as shown in Figure 5.

Over the last half century, researchers have proposed several empirical equations to describe the attenuation characteristics of blast vibrations and predict the attenuation of the PPV [26-28]. The PPV equations that have been proposed by different researchers are summarized in Table 2. In most of these equations, the distance from the free face and the maximum charge weight per delay are considered the main parameters influencing PPV prediction. However, is well known that PPV is influenced by other factors, such as the rock strength, rock mass discontinuity conditions, and blast geometry, which have not been explicitly incorporated in these empirical equations. In this study, the NichollsUnited States Bureau of Mines (USBM) empirical equation is used as the prediction equation.

2.3. Wavelet Packet Analysis Method. Wavelet packet analysis is a time-frequency processing method for a nonstationary random signal. This signal is decomposed into two parts, i.e., the low and high frequencies, using low- and high-pass filters, respectively. The two decomposed signals are then further divided into two parts corresponding to the low and high frequencies. Thus, the signal is continuously decomposed, thereby exhibiting a high-frequency resolution [29]. Analysis of the signal continued to the eighth decomposition level. The signal decomposition process is illustrated in Figure 6. The number of frequency bands in the blasting vibration signals at approximately $2^{n}$ can be obtained, such that $n$ is the decomposition level of the wavelet packet analysis. If the lowest frequency of the blast vibration signal, $s(t)$, is 0 and the highest frequency is $W$, the width of 


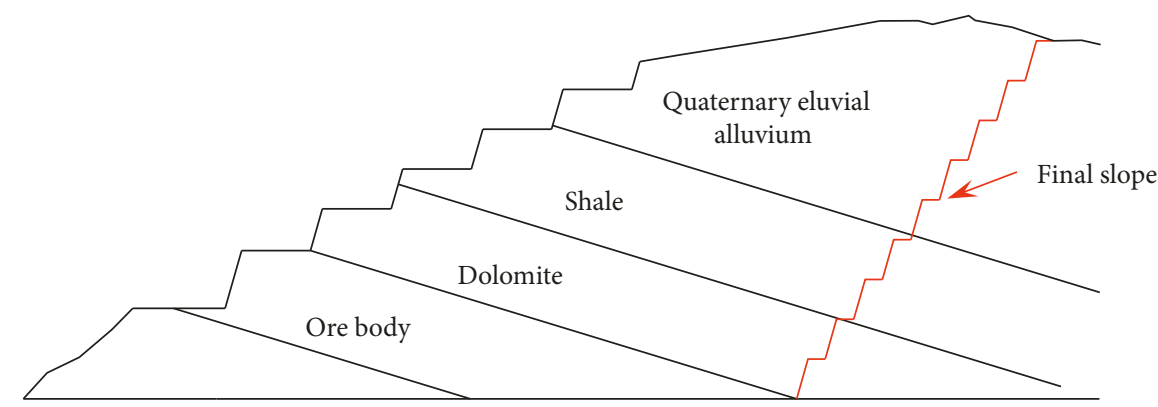

FIGURE 1: Geological profile of Baideng phosphorite.

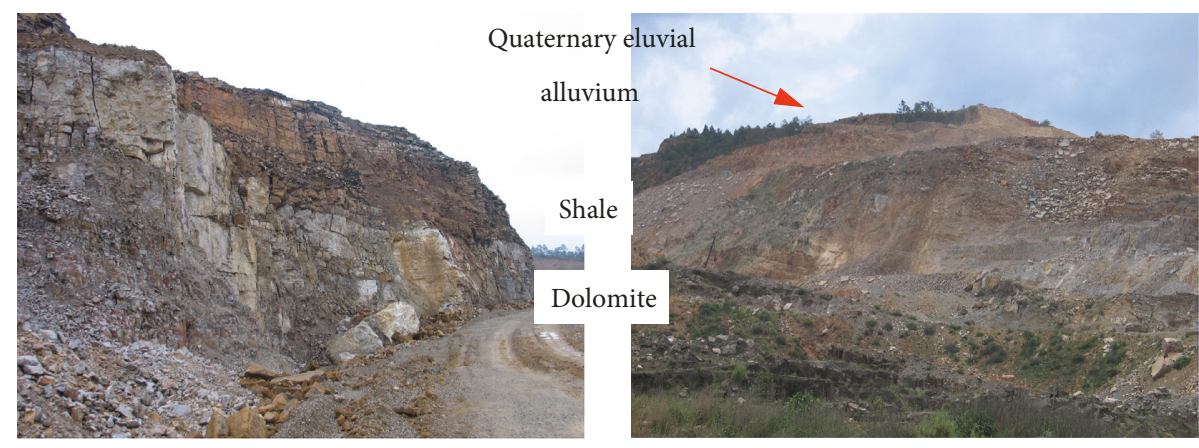

FIgURE 2: Bench of Baideng phosphorite.

TABle 1: Mechanical parameters of rock masses.

\begin{tabular}{lccccccc}
\hline Rock type & UCS $(\mathrm{MPa})$ & TS $(\mathrm{MPa})$ & $\rho\left(\mathrm{g} / \mathrm{cm}^{3}\right)$ & $E(\mathrm{GPa})$ & $\mathrm{JF}$ & $V_{\mathrm{r}}(\mathrm{m} / \mathrm{s})$ & $V_{\mathrm{rm}}(\mathrm{m} / \mathrm{s})$ \\
\hline Dolomite & 95.73 & 16.48 & 3.53 & 87.62 & 2.1 & 5247 & 2471 \\
Shale & 58.21 & 5.84 & 2.69 & 55.85 & 0.9 & 3813 & 2895 \\
\hline
\end{tabular}

Note. UCS: uniaxial compression strength; TS: tensile strength; $\rho$ : dry density; $E$ : Young's modulus; $V_{\mathrm{r}}$ : wave velocity of rock; $V_{\mathrm{rm}}$ : wave velocity of rock mass; JF: number of joints per $10 \mathrm{~m}$.

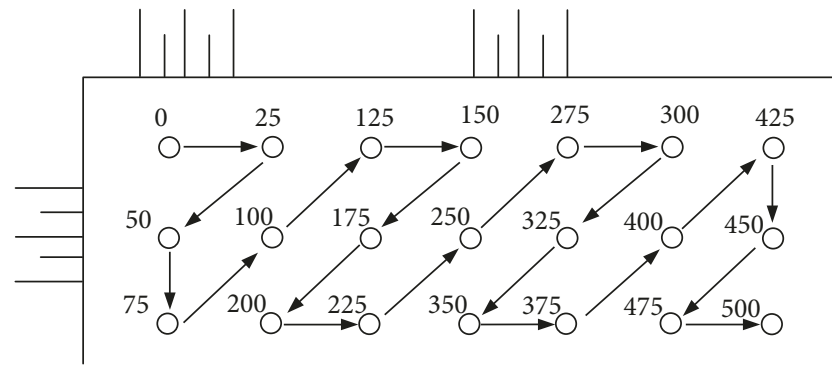

FIGURE 3: Initiation network and drilling holes pattern.

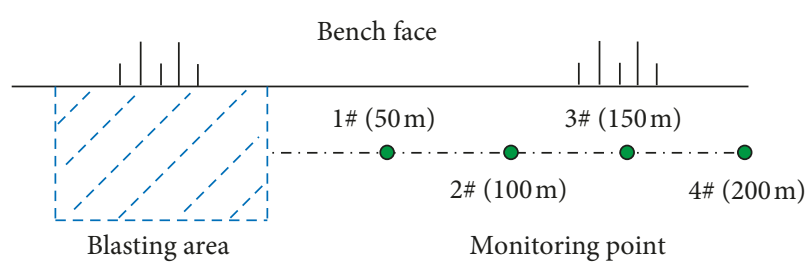

FigURE 4: Diagram for location of blasting vibration monitoring.

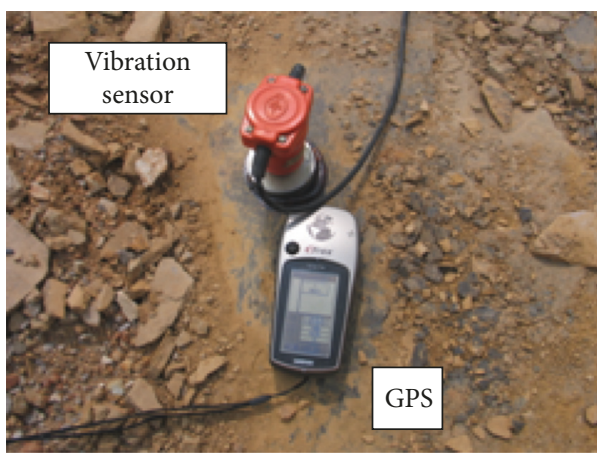

FIGURE 5: Vibration sensor and GPS.

the frequency band at the $n$th decomposition level will be $W / 2^{n}$

Based on the decomposition and reconstruction of the wavelet packet analysis method, the blast vibration signal, $s(t)$, can be expressed as follows: 
TABLE 2: Empirical PPV predictor presented by different researches.

\begin{tabular}{lr}
\hline Name & Equation \\
\hline Nicholls-USBM & $P P V=k\left[Q^{1 / 2} / R\right]^{n}$ \\
General Prediction by Davies & $P P V=k R^{-n} Q^{a}$ \\
Langefors and Kihlstrom & $P P V=k\left[Q^{1 / 2} / R^{1 / 3}\right]^{n}$ \\
Bureau of Indian Standard & $P P V=k\left[Q / R^{2 / 3}\right]^{n}$ \\
Ambressys-Hendron & $P P V=k\left[Q^{1 / 3} / R\right]^{n}$ \\
Ghosh-Daemen predictor & $P \mathrm{PV}=k\left[R / Q^{1 / 2}\right]^{-n} e^{-\alpha R}$ \\
\hline
\end{tabular}

Note. $R$ : distance from the blast area to the vibration monitoring point; $Q$ : maximum charge weight per delay; $k, n, a, \alpha$ : site constants.

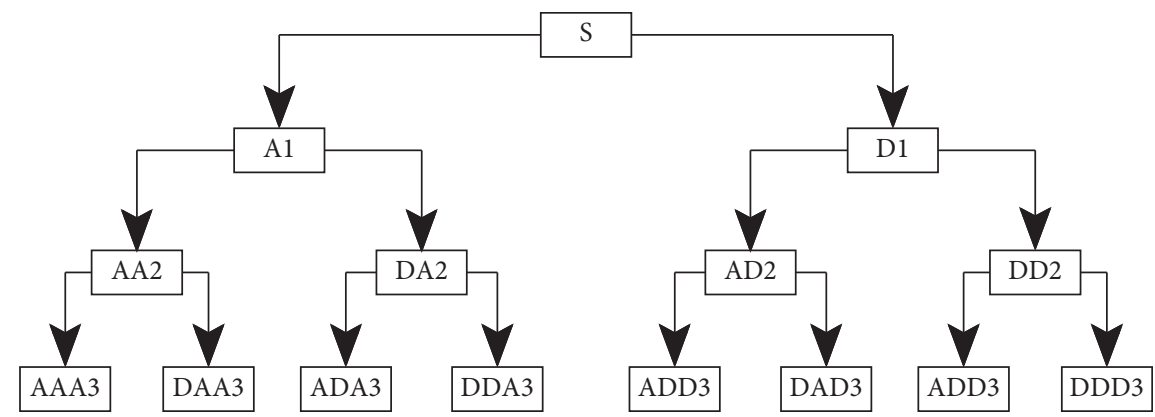

Figure 6: Diagram for signal decomposition process. A stands for low frequency, D stands for high frequency, and the numbers 1, 2, and 3 stands for decomposition levels.

$$
s(t)=\sum_{j}^{2^{i}-1} s_{i, j}
$$

where $s_{i, j}$ is the reconstructed signal after wavelet packet decomposition, $i$ is the decomposition level, and $j$ is the order number of the frequency bands after decomposition, $j=0,1,2,3, \ldots, 2^{i}-1$.

The energy of each reconstructed signal, $E_{i, j}$, after wavelet packet decomposition is defined as

$$
E_{i, j}=\int\left|s_{i, j}(t)\right|^{2} d t=\sum_{k=1}^{m}\left|x_{j, k}\right|^{2},
$$

where $x_{i, j}$ is the amplitude of the discrete points of the reconstructed signal, $m$ is the number of discrete sampling points, and $k$ is the number of discrete points, $k=1,2,3, \ldots, m$.

The total energy of the analyzed signal, $E_{0}$, is expressed as follows:

$$
E_{0}=\sum_{j=0}^{2^{i}-1} E_{i, j}
$$

The ratio of the energy in each frequency band to the total energy can be derived as follows:

$$
P_{j}=\frac{E_{i, j}}{E_{0}} \times 100 \% \text {. }
$$

\section{Results and Discussion}

Approximately 24 events from 6 blasts were recorded at the Baideng phosphorite open-pit mine, as summarized in Table 3 . The blasting areas were grouped into two locations: the dolomite bench and the shale bench. Figure 7 shows the velocity histories of the blasting vibration monitoring.

3.1. Attenuation Law for the PPV of Blasting Vibration. The relationship between PPV and scaled distance revealed by the blasting vibration test data is shown in Figure 8 . The PPV of the dolomite and shale decreases steadily with increasing scaled distance. The PPV is larger in the dolomite than in the shale for a constant scaled distance. Lu et al. [30] reported that the total energy of a blast-induced seismic activity is directly proportional to the square of the PPV during the same blasting. Therefore, more explosive energy was converted to rock mass vibration in the dolomite bench than that in the shale bench. The field data were analyzed by regression using the least squares fitting method. The attenuation equations for dolomite $\left(\mathrm{PPV}_{\mathrm{d}}\right)$ and shale $\left(\mathrm{PPV}_{\mathrm{s}}\right)$ are presented as follows:

$$
\begin{aligned}
& \operatorname{PPV}_{d}=3852\left(\frac{\sqrt{Q}}{R}\right)^{2.57}, \\
& \operatorname{PPV}_{\mathrm{s}}=1367\left(\frac{\sqrt{Q}}{R}\right)^{1.94} .
\end{aligned}
$$

These relationships indicate that the PPV decays proportionally to $1 / R^{2.57}$ for the dolomite and $1 / R^{1.94}$ for the shale with increasing distance for a constant explosive charge weight. The relationships also indicate that PPV decreases more rapidly in dolomite than shale.

3.2. Attenuation Law of Energy for Blasting Vibration. The sampling rate of the monitoring equipment during the blasting vibration monitoring is $0-4 \mathrm{kHz}$. Following the 
TABLE 3: Summary of the blasting-induced vibration data at Baideng phosphorite.

\begin{tabular}{|c|c|c|c|c|c|c|c|c|c|}
\hline \multirow{2}{*}{ No. } & \multicolumn{4}{|c|}{ Dolomite } & \multirow{2}{*}{ No. } & \multicolumn{4}{|c|}{ Shale } \\
\hline & JF & $Q(\mathrm{~kg})$ & $R(\mathrm{~m})$ & $\mathrm{PPV}(\mathrm{mm} / \mathrm{s})$ & & $\mathrm{JF}$ & $Q(\mathrm{~kg})$ & $R(\mathrm{~m})$ & $\mathrm{PPV}(\mathrm{mm} / \mathrm{s})$ \\
\hline \multirow{5}{*}{ D1 } & \multirow{4}{*}{2.4} & \multirow{4}{*}{100} & 46 & 69.799 & \multirow{4}{*}{ S1 } & \multirow{4}{*}{0.8} & \multirow{4}{*}{75} & 57 & 39.461 \\
\hline & & & 97 & 14.713 & & & & 112 & 15.026 \\
\hline & & & 151 & 3.771 & & & & 168 & 7.815 \\
\hline & & & 202 & 0.963 & & & & 215 & 2.231 \\
\hline & \multirow{4}{*}{2.7} & \multirow{4}{*}{96} & 55 & 65.726 & \multirow{4}{*}{ S2 } & \multirow{4}{*}{1.2} & \multirow{4}{*}{87} & 73 & 27.564 \\
\hline \multirow{3}{*}{ D2 } & & & 105 & 6.285 & & & & 133 & 13.566 \\
\hline & & & 147 & 2.168 & & & & 185 & 6.258 \\
\hline & & & 198 & 0.884 & & & & 223 & 1.083 \\
\hline \multirow{4}{*}{ D3 } & \multirow{4}{*}{1.8} & \multirow{4}{*}{98} & 48 & 45.739 & \multirow{4}{*}{ S3 } & \multirow{4}{*}{1.0} & \multirow{4}{*}{80} & 55 & 23.216 \\
\hline & & & 111 & 12.218 & & & & 97 & 9.843 \\
\hline & & & 172 & 5.375 & & & & 152 & 4.761 \\
\hline & & & 237 & 1.832 & & & & 201 & 2.926 \\
\hline
\end{tabular}
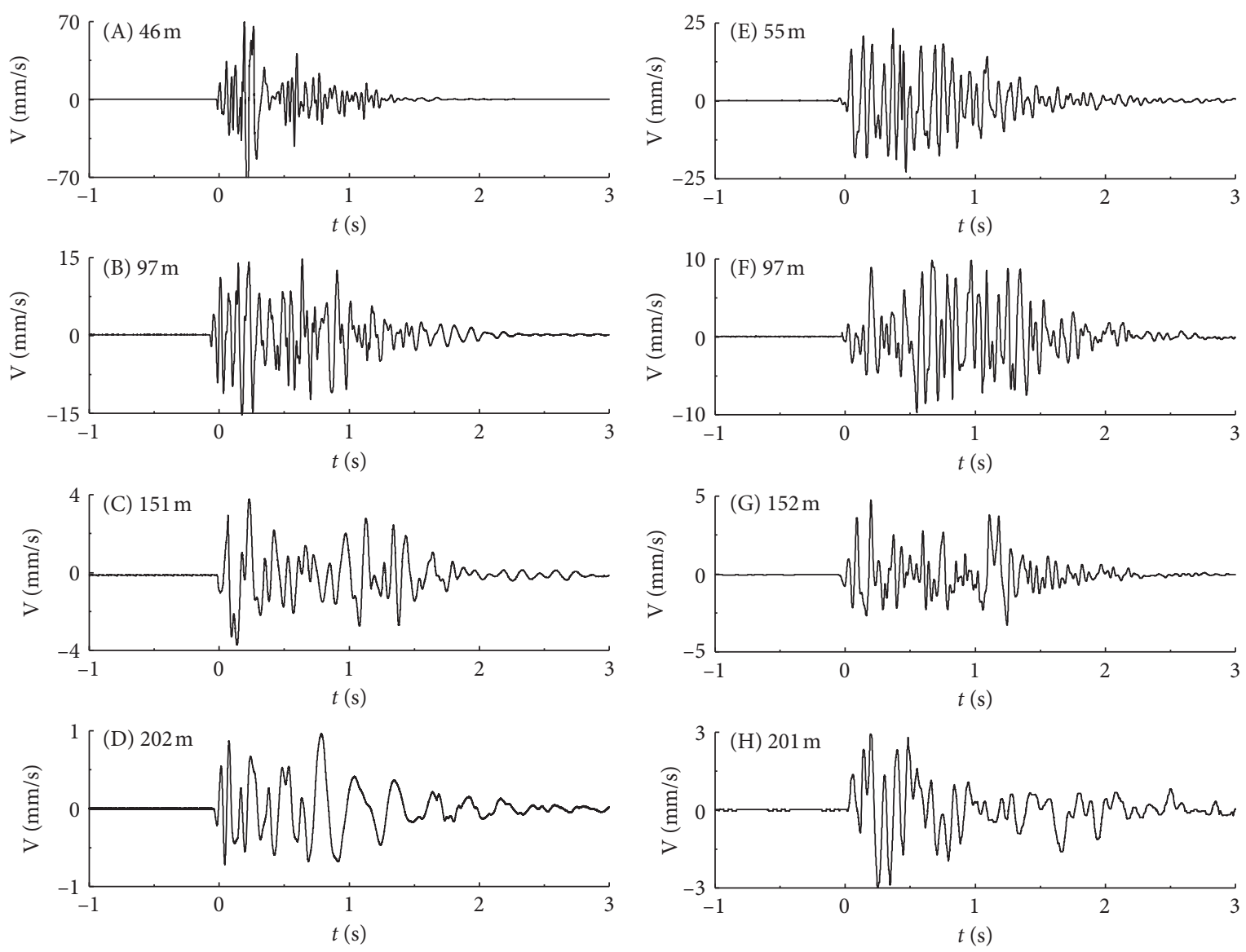

(a)

(b)

FIgURE 7: The velocity histories of blasting vibration monitoring. (a) D1. (b) S3.

Nyquist sampling theory, the highest frequency of the signals being analyzed is $2 \mathrm{kHz}$. The Daubechies wavelet series exhibits smoothness, compact support, and symmetry compared to a conventional wavelet. This wavelet series has been widely used in the analysis of blasting vibration signals. In this study, the blasting vibration signal was decomposed into nine layers using wavelet packet analysis, and $2^{9}$ frequency bands were generated in which each frequency band is $2000 / 2^{9}=3.90625 \mathrm{~Hz}$.

The blast vibration signals underwent decomposition and reconstruction using $\mathrm{db} 5-\mathrm{db} 10$ in the wavelet packet according to Equations (2) and (4), respectively. The errors in the reconstructed signals are listed in Table 4 . The statistics in Table 4 indicate that the $\mathrm{db} 8$ wavelet packet has the 


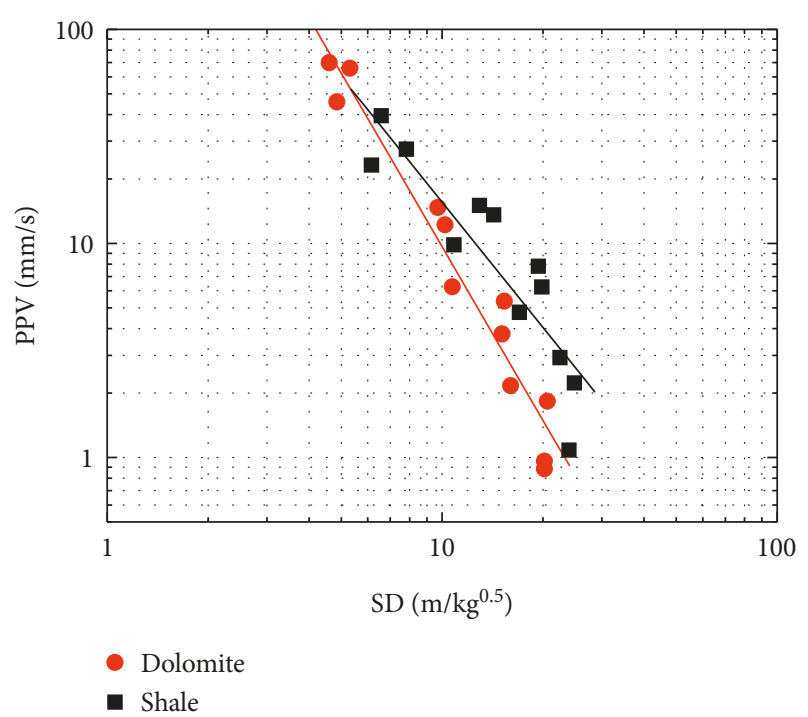

Figure 8: Scaled distance versus PPV of different positions at Baideng phosphorite.

smallest reconstruction error; thus, $\mathrm{db} 8$ is used to analyze the time-frequency energy of the signal in Figure 6. The energy distribution of the wavelet packet frequency band for the blasting vibration signals was obtained for the dolomite and shale. The results are listed in Table 5.

The results presented in Table 5 indicate that the energy of the blast vibration signal is widely distributed in the frequency band; however, most of the energy is concentrated at $0-50.78125 \mathrm{~Hz}$. The energy ratios for the eight signals at $0-50.78125 \mathrm{~Hz}$ that comprise the total energy are $93.537 \%$, $97.24 \%, 99.867 \%, 99.91 \%, 97.88 \%, 98.94 \%, 98.52 \%$, and 99.88\%. In Figure 9, the time-frequency spectrum distribution is considered in the range of $0-50 \mathrm{~Hz}$ to compare the influence of rock properties and propagation distance on the distribution of blasting vibration energy. The main vibration frequencies of the blasting vibration in dolomite and shale at a distance of $50 \mathrm{~m}$ from the blast area are 25 and $14 \mathrm{~Hz}$, respectively. The main vibration frequency decreases gradually with increasing distance from the blast area to the vibration monitoring point. The main vibration frequencies of dolomite and shale are less than $5 \mathrm{~Hz}$ at a distance from the blast area of $200 \mathrm{~m}$.

The upper limit of the natural vibration frequency of a ground building is $10 \mathrm{~Hz}$. The energy of the blasting vibration waves is in the range of $0-20 \mathrm{~Hz}$ and has an obvious effect on buildings. Therefore, the blasting vibration wave in this study is divided into primary $(0-20 \mathrm{~Hz})$ and secondary $(20-50 \mathrm{~Hz})$ influence frequency bands, and the energy attenuation law for the different frequency bands is analyzed. The energy of each frequency band is subject to a normalized analysis. The energy attenuation laws for the blasting vibration in different rock masses and frequency bands are shown in Figure 10. In Figure 10, at distances of 50-200 m from the blast area to the vibration monitoring point, the attenuation rate for the dolomite and shale blasting is lower in the primary influence frequency band than in the secondary influence frequency band. The attenuation is lower in
TABLE 4: Reconstruction errors of wavelet packet analysis.

\begin{tabular}{lcccccc}
\hline $\mathrm{db} N$ & $\mathrm{db} 5$ & $\mathrm{db} 6$ & $\mathrm{db} 7$ & $\mathrm{db} 8$ & $\mathrm{db} 9$ & $\mathrm{db} 10$ \\
\hline Error value $\left(10^{-10}\right)$ & 9.896 & 7.708 & 4.141 & 2.537 & 14.81 & 15.29 \\
\hline
\end{tabular}

the shale blasting than in the dolomite blasting for the same frequency band. Figures 9 and 10 show that, in the nearblasting field (less than $50 \mathrm{~m}$ ), the blasting vibration velocity and vibration energy of dolomite are higher than that of shale, and more vibration energy is distributed in the higher frequency range. In the far-blasting field (more than $50 \mathrm{~m}$ ), the decay rate of the vibration velocity and energy attenuation of the blasting vibration of dolomite is higher than that of shale. The rock mechanics parameters in Table 1 indicate that the uniaxial compression strength, tensile strength, and elastic modulus of dolomite are higher than that of shale, but the dolomite also had more developed joints than the shale. These results demonstrate that, in the near-blasting field, the vibration attenuation of blasting is mainly affected by the mechanical properties of the rock; with increasing rock strength and elastic modulus, the blasting vibration velocity and vibration energy also increased, which is consistent with the testing results reported by Xu et al. [31]. However, in the far-blasting field, the vibration attenuation of blasting is mainly affected by the structural characteristics of the rock mass; with increasing number of joints in the rock mass, the attenuation rate of the vibration velocity and energy attenuation of blasting vibration increased. Therefore, under geological conditions leading to joint development, the function of the joint should be considered in blasting vibration predictions.

3.3. Development of a New Relationship. For simplicity, the distance from the blast area to the vibration monitoring point $(R)$ and then to the square root of the maximum explosive charge per delay $(Q)$ is called the scaled distance (SD), and their relationship can be expressed as follows:

$$
\mathrm{SD}=R Q^{-1 / 2} \text {. }
$$

The PPV prediction with the Nicholls-USBM equation is written as follows:

$$
\mathrm{PPV}=k(\mathrm{SD})^{-n}=k\left(\frac{\sqrt{\mathrm{Q}}}{R}\right)^{n}
$$

where $k$ is the attenuation constant and $n$ is the attenuation index.

The results shown in Figure 10 indicate that the attenuation law of the blasting vibration was affected by the number of joints in the rock mass. The influence of rock mass joints on the attenuation law of the blasting vibration should be considered comprehensively to predict the exact PPV of blasting, and thus the attenuation equation needs to be modified. According to the studies conducted by Simangunsong and Wahyudi [32], the influence of the number of coal seams should be considered in the prediction of blasting vibration. The proposed modified equation for PPV and SD can be expressed as follows: 
TABLE 5: The wavelet packet frequency band energy distribution for blasting vibration signals.

\begin{tabular}{|c|c|c|c|c|c|c|c|c|}
\hline \multirow{2}{*}{ Frequency band $(\mathrm{Hz})$} & \multicolumn{4}{|c|}{ D1 } & \multicolumn{4}{|c|}{ S3 } \\
\hline & $46(\mathrm{~m})$ & $97(\mathrm{~m})$ & $151(\mathrm{~m})$ & $202(\mathrm{~m})$ & $55(\mathrm{~m})$ & $97(\mathrm{~m})$ & $152(\mathrm{~m})$ & $201(\mathrm{~m})$ \\
\hline $0 \sim 3.90625$ & $2.82 E-02$ & $2.42 E-04$ & $3.35 E-03$ & $8.09 E-03$ & $2.37 E+00$ & $4.28 E+00$ & $6.84 E+00$ & $4.01 E+01$ \\
\hline $3.90625 \sim 7.8125$ & $3.07 E-02$ & $2.03 E-02$ & $1.52 E-02$ & $3.87 E-03$ & $7.39 E+00$ & $1.40 E+01$ & $3.05 E+01$ & $9.76 E+00$ \\
\hline $7.8125 \sim 11.71875$ & $5.49 E-01$ & $4.38 E-02$ & $2.87 E-03$ & $2.38 E-03$ & $1.62 E+01$ & $3.11 E+01$ & $1.72 E+01$ & $1.29 E+01$ \\
\hline $11.71875 \sim 15.625$ & $4.95 E-01$ & $3.96 E-02$ & $8.55 E-03$ & $1.75 E-03$ & $4.57 E+01$ & $2.51 E+01$ & $1.78 E+01$ & $3.35 E+01$ \\
\hline $15.625 \sim 19.53125$ & $5.43 E-01$ & $2.83 E-03$ & $5.62 E-05$ & $6.60 E-06$ & $1.81 E+00$ & $2.06 E+00$ & $1.40 E+00$ & $1.08 E-01$ \\
\hline $19.53125 \sim 23.4375$ & $1.84 E-01$ & $6.83 E-03$ & $1.06 E-04$ & $1.67 E-05$ & $3.05 E+00$ & $2.90 E+00$ & $3.21 E+00$ & $9.02 E-02$ \\
\hline $23.4375 \sim 27.34375$ & $1.62 E+00$ & $9.94 E-03$ & $2.61 E-03$ & $2.83 E-04$ & $1.68 E+01$ & $1.55 E+01$ & $1.32 E+01$ & $2.01 E+00$ \\
\hline $27.34375 \sim 31.25$ & $3.72 E-01$ & $9.32 E-03$ & $5.76 E-04$ & $1.40 E-04$ & $3.37 E+00$ & $2.99 E+00$ & $7.84 E+00$ & $1.27 E+00$ \\
\hline $31.25 \sim 35.15625$ & $2.01 E-02$ & $7.51 E-05$ & $1.51 E-06$ & $1.80 E-08$ & $1.21 E-02$ & $1.40 E-02$ & $7.85 E-04$ & $8.70 E-03$ \\
\hline $35.15625 \sim 39.0625$ & $1.28 E-02$ & $1.38 E-04$ & $2.43 E-06$ & $6.44 E-08$ & $2.99 E-02$ & $1.05 E-02$ & $2.57 E-03$ & $1.13 E-02$ \\
\hline $39.0625 \sim 42.96875$ & $1.50 E-02$ & $1.32 E-03$ & $7.52 E-06$ & $3.91 E-07$ & $1.61 E-01$ & $1.84 E-02$ & $3.10 E-02$ & $8.79 E-02$ \\
\hline $42.96875 \sim 46.875$ & $1.58 E-02$ & $2.64 E-04$ & $3.95 E-06$ & $2.70 E-07$ & $2.80 E-02$ & $2.02 E-02$ & $1.73 E-02$ & $1.13 E-02$ \\
\hline $46.875 \sim 50.78125$ & $3.17 E-01$ & $1.09 E-03$ & $1.87 E-05$ & $2.13 E-06$ & $9.40 E-01$ & $8.83 E-01$ & $4.79 E-01$ & $2.45 E-02$ \\
\hline $50.78125 \sim 101.5625$ & $2.12 E-01$ & $3.70 E-03$ & $3.83 E-05$ & $1.06 E-05$ & $1.86 E-02$ & $1.44 E-03$ & $2.98 E-04$ & $2.97 E-06$ \\
\hline $101.5625 \sim 203.125$ & $5.74 E-02$ & $1.48 E-04$ & $2.67 E-06$ & $1.64 E-07$ & $1.79 E-03$ & $6.70 E-05$ & $4.79 E-06$ & $1.77 E-06$ \\
\hline $203.125 \sim 300.78125$ & $3.87 E-03$ & $9.82 E-07$ & $8.22 E-07$ & $6.79 E-08$ & $1.90 E-04$ & $7.50 E-06$ & $6.89 E-07$ & $1.77 E-07$ \\
\hline $300.78125 \sim 500$ & $1.03 E-02$ & $6.78 E-07$ & $1.65 E-06$ & $1.93 E-07$ & $9.14 E-06$ & $6.71 E-07$ & $3.06 E-08$ & $1.87 E-07$ \\
\hline $500 \sim 1000$ & $3.86 E-03$ & $4.74 E-06$ & $3.07 E-06$ & $1.62 E-06$ & $9.67 E-08$ & $1.61 E-07$ & $1.08 E-09$ & $1.22 E-07$ \\
\hline 1000 2000 & $2.42 E-03$ & $3.53 E-07$ & $3.21 E-07$ & $1.59 E-06$ & $4.18 E-09$ & $1.60 E-07$ & $4.30 E-10$ & $1.13 E-07$ \\
\hline
\end{tabular}
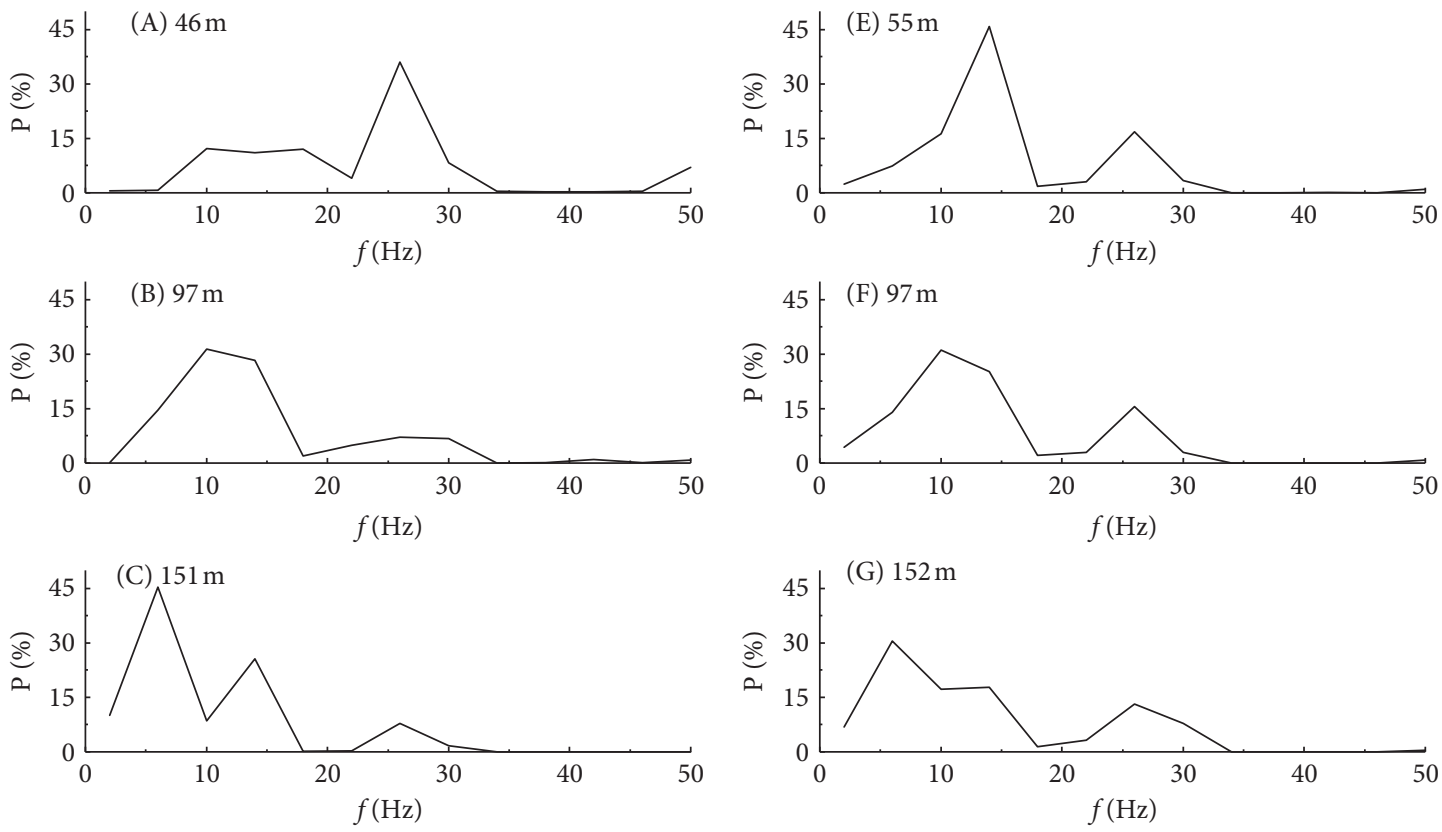

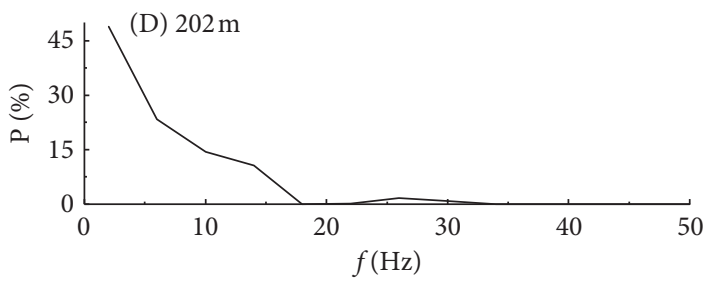

(a)

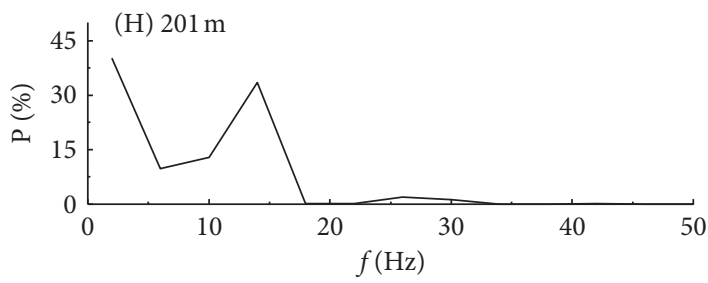

(b)

Figure 9: Time-frequency energy spectrum distributions for blast vibration signals. (a) D1. (b) S3. 


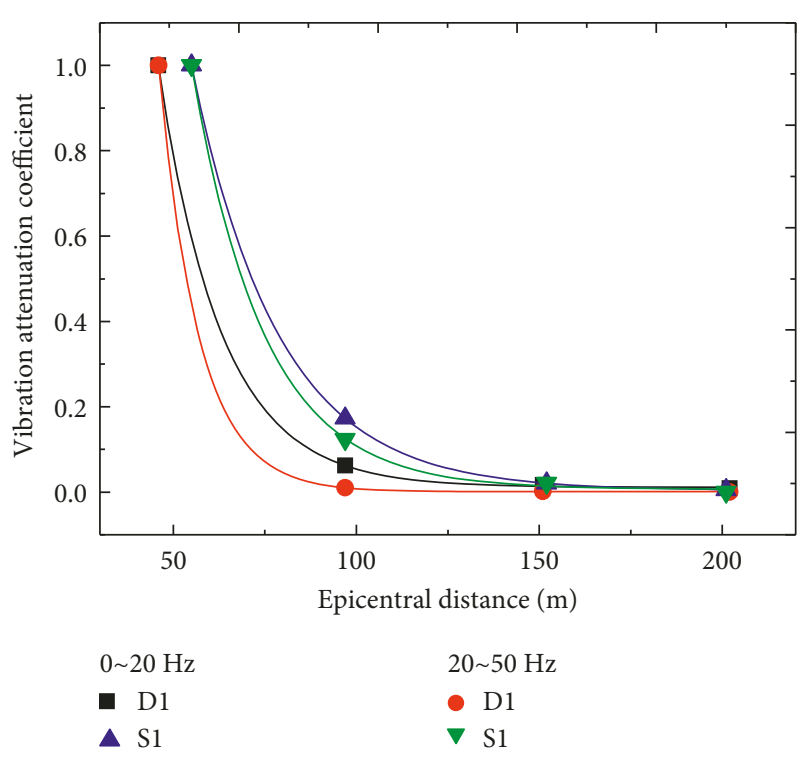

Figure 10: The energy attenuation law of different frequency bands.

$$
\mathrm{PPV}=k\left(\mathrm{SD}_{\mathrm{JF}}\right)^{-n}=k\left\{[1+\log (1+\mathrm{JF} \times R)] \frac{R}{\sqrt{Q}}\right\}^{-n}
$$

If JR is 0 , then the new $\mathrm{SD}_{\mathrm{JF}}$ will become the original $\mathrm{SD}$ (Equation (6)), in which no influence of the joint plane is considered in the prediction of PPV.

A total of 24 ground vibration readings at the Baideng open-pit phosphorite mine are listed in Table 2 and were used to examine the relationship between PPV, SD, and $\mathrm{SD}_{\mathrm{JF}}$. The results are plotted in Figure 11. The modified equation $\mathrm{PPV}_{\mathrm{JF}}$ exhibits a better correlation factor $\left(R^{2}\right)$ than the original Nicholls-USBM relationship PPV; the correlation factors are 0.85 and 0.80 , respectively. The newly modified equation, which considers the effect of joints, demonstrates superior accuracy and applicability for predicting blasting vibration at the Baideng open-pit phosphorite mine.

In an open-pit minefield, different rock properties are observed between the blasting area and the monitoring point, thereby corresponding to different joint degrees, as shown in Figure 12. JF in the different rock masses are expressed by $\mathrm{JF}_{1}, \mathrm{JF}_{2}, \ldots, \mathrm{JF}_{\mathrm{i}}$, and the distances are expressed by $R_{1}, R_{2}, \ldots, R_{i}$, respectively. Therefore, Equation (8) can be expressed as follows:

$$
\mathrm{PPV}=k\left\{\left[1+\log \left(1+\sum \mathrm{JF}_{i} \cdot R_{i}\right)\right] \frac{R}{\sqrt{\mathrm{Q}}}\right\}^{-n} .
$$

A total of 15 vibration readings were obtained from the Baideng open-pit phosphorite mine, in which the blasting areas and monitoring points are located in the different rock masses, i.e., shale and dolomite, as summarized in Table 6.

The modified equation and Nicholls-USBM empirical equation were then used to predict the PPV of the remaining readings. The results are shown in Figure 13, in which the

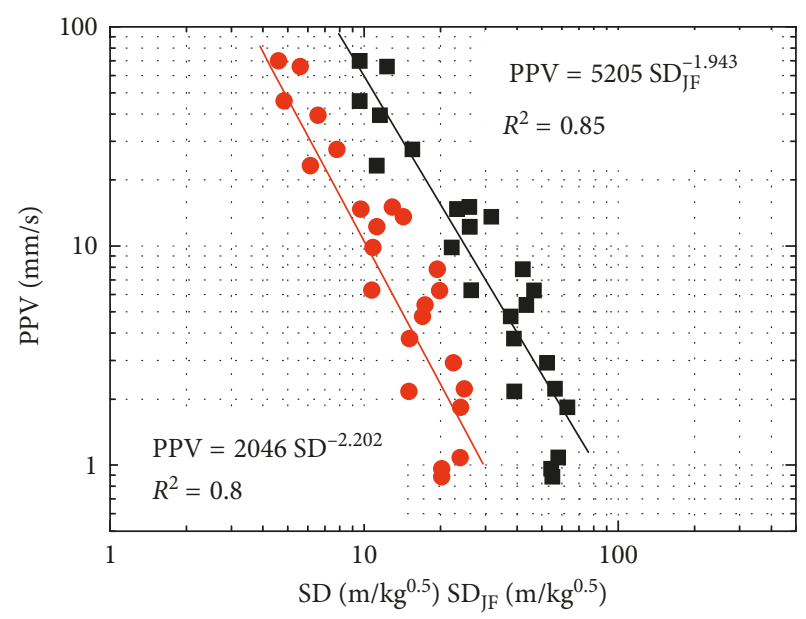

FIgURE 11: Relationships between PPV and SD and $\mathrm{SD}_{\mathrm{JF}}$.

monitored PPV is compared with the predicted results. In Figure 13, the PPV predicted by the modified equation is visually a better fit for the monitoring data than that predicted by the Nicholls-USBM equation. In particular, the prediction results are greater than the monitored data for predicting strong vibrations, which will benefit the analysis of slope stability during blasting. The results demonstrate that the modified equation can be used for predicting the PPV of blasting engineering in the Baideng open-pit phosphorite mine and that the accuracy of the predictions is acceptable.

\section{Conclusions}

In this study, blasting vibration signals were monitored for dolomite and shale blasting areas in the Baideng open-pit phosphorite mine. Moreover, the effect of attenuation laws on the blasting vibration signals in rock masses having different properties was analyzed using the wavelet packet time-frequency analysis method. Based on the results, the following conclusions can be made:

(1) The blasting vibration attenuation coefficient exhibits a clear relationship with the rock mass. The attenuation law coefficient, $k$, and $n$ for the blasting vibration waves were $(3852,2.57)$ and $(1367,1.94)$ at the dolomite and shale blasting areas in the Baideng open-pit mine, respectively. The attenuation rates of the PPV and energy are higher in the dolomite than in the shale.

(2) The blasting vibration signal spectra based on the wavelet packet time-frequency analysis are mainly composed of low frequencies, whereas the spectra of the blasting vibration signals are mainly composed of low frequencies, with the main vibration frequency in the range of $0-50 \mathrm{~Hz}$. The main vibration frequency decreases with increasing distance to the monitoring points.

(3) The degree of development that the rock mass joints have undergone influences the attenuation rate of the PPV, and the PPV attenuation rate is high when the number of joints in the rock mass is high. A new 


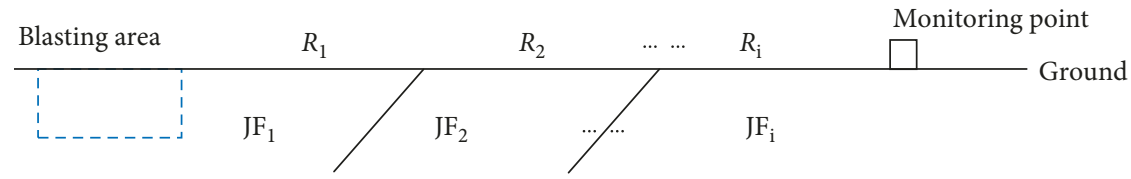

FIgURE 12: Schematic diagram of lithology changes between blasting area and monitoring point.

TABLE 6: The blasting vibration data at bench of different rock properties.

\begin{tabular}{|c|c|c|c|c|c|c|c|c|c|c|}
\hline \multirow{2}{*}{ No. } & \multirow{2}{*}{$Q(\mathrm{~kg})$} & \multirow{2}{*}{$R_{\mathrm{s}}^{*}(\mathrm{~m})$} & \multirow{2}{*}{$R_{\mathrm{D}}(\mathrm{m})$} & \multirow{2}{*}{$\mathrm{JF}_{\mathrm{S}}$} & \multirow{2}{*}{$\mathrm{JF}_{\mathrm{D}}$} & \multirow{2}{*}{$\mathrm{PPV}(\mathrm{mm} / \mathrm{s})$} & \multirow{2}{*}{$\mathrm{PPV}_{1}(\mathrm{~mm} / \mathrm{s})$} & \multirow{2}{*}{$\mathrm{PPV}_{\mathrm{JF}}(\mathrm{mm} / \mathrm{s})$} & \multicolumn{2}{|c|}{ Difference (\%) } \\
\hline & & & & & & & & & $\mathrm{PPV}_{1}$ & $\mathrm{PPV}_{\mathrm{JF}}$ \\
\hline 1 & 1900 & 57 & 144 & 0.5 & 2.0 & 8.579 & 8.551 & 6.765 & 0 & 21 \\
\hline 2 & 660 & 76 & 177 & 1.3 & 2.7 & 0.346 & 1.676 & 1.231 & 385 & 256 \\
\hline 3 & 660 & 76 & 122 & 1.3 & 2.7 & 1.554 & 2.837 & 2.203 & 83 & 42 \\
\hline 4 & 660 & 76 & 71 & 1.3 & 2.7 & 8.087 & 5.379 & 4.530 & 33 & 44 \\
\hline 5 & 500 & 49 & 147 & 1.2 & 2.3 & 0.757 & 2.152 & 1.747 & 184 & 131 \\
\hline 6 & 500 & 49 & 203 & 1.2 & 2.3 & 0.467 & 1.254 & 0.969 & 169 & 108 \\
\hline 7 & 95 & 5 & 98 & 0.9 & 1.2 & 5.748 & 1.440 & 1.819 & 75 & 68 \\
\hline 8 & 3515 & 102 & 15 & 0.5 & 1.5 & 61.029 & 52.937 & 62.651 & 13 & 3 \\
\hline 9 & 3515 & 136 & 39 & 0.5 & 1.5 & 18.631 & 22.293 & 22.777 & 20 & 22 \\
\hline 10 & 1770 & 150 & 713 & 1.0 & 2.6 & 0.158 & 0.346 & 0.201 & 120 & 27 \\
\hline 11 & 830 & 87 & 3 & 0.3 & 2.4 & 33.838 & 19.737 & 34.558 & 42 & 2 \\
\hline 12 & 126 & 216 & 114 & 0.8 & 1.4 & 0.149 & 0.160 & 0.166 & 7 & 12 \\
\hline 13 & 81 & 134 & 206 & 0.5 & 1.3 & 0.105 & 0.093 & 0.101 & 11 & 4 \\
\hline 14 & 81 & 134 & 66 & 0.5 & 1.3 & 1.538 & 0.292 & 0.381 & 81 & 75 \\
\hline 15 & 81 & 60 & 10 & 0.5 & 1.3 & 7.521 & 2.782 & 5.061 & 63 & 33 \\
\hline
\end{tabular}

$R_{\mathrm{S}, \mathrm{D}}$ : distances of shale or dolomite; $\mathrm{JF}_{\mathrm{S}, \mathrm{D}}$ : number of joints in shale or dolomite per $10 \mathrm{~m} ; \mathrm{PPV}_{1}$ : predicted PPV by Nicholls-USBM; PPV $\mathrm{JF}_{\mathrm{F}}$ : predicted PPV by modified relationship.

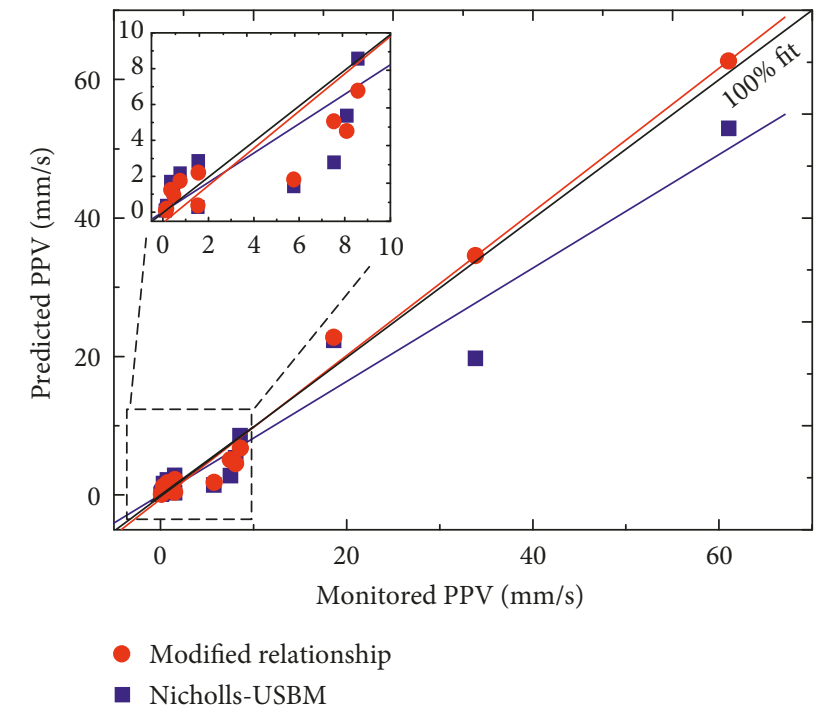

FIgURE 13: Comparison between predicted and monitored PPV.

relationship was developed to improve the prediction of PPV in the different rock masses of the open-pit mine by accounting for the degree of development and number of joints in the rock mass.

\section{Data Availability}

The data used to support the findings of this study are included within the article.

\section{Conflicts of Interest}

The authors declare that there are no conflicts of interest regarding the publication of this paper.

\section{Acknowledgments}

This work was supported by the Anhui Provincial Natural Science Foundation (1808085ME159 and 1808085QE149), National Natural Science Foundation of China (51774014), Science and Technology Planning Project of Anhui Province (1604a0802107), Program for Innovative Research Team in the University of Anhui Province (Prevention and Control of Coal Rock Dynamic Disasters in Deep Coal Mine), and Natural Science Foundation of the Anhui Higher Education Institutions (KJ2017A093).

\section{References}

[1] D. J. Armaghani, M. Hajihassani, E. T. Mohamad, A. Marto, and S. A. Noorani, "Blasting-induced flyrock and ground vibration prediction through an expert artificial neural network based on particle swarm optimization," Arabian Journal of Geosciences, vol. 7, no. 12, pp. 5383-5396, 2014.

[2] P. K. Singh, M. P. Roy, R. K. Paswan, R. K. Dubey, and C. Drebenstedt, "Blast vibration effects in an underground mine caused by open-pit mining," International Journal of Rock Mechanics and Mining Sciences, vol. 80, pp. 79-88, 2015.

[3] G. R. Tripathy and I. D. Gupta, "Prediction of ground vibrations due to construction blasts in different types of rock," Rock Mechanics and Rock Engineering, vol. 35, no. 3, pp. 195-204, 2002. 
[4] W. M. Yan, L. G. Tham, and K. V. Yuen, "Reliability of empirical relation on the attenuation of blast-induced vibrations," International Journal of Rock Mechanics and Mining Sciences, vol. 59, pp. 160-165, 2013.

[5] X. Fan, K. Li, H. Lai, Y. Xie, R. Cao, and J. Zheng, "Internal stress distribution and cracking around flaws and openings of rock block under uniaxial compression: a particle mechanics approach," Computers and Geotechnics, vol. 102, pp. 28-38, 2018.

[6] X. Fan, R. Chen, H. Lin, H. Lai, C. Zhang, and Q. Zhao, "Cracking and failure in rock specimen containing combined flaw and hole under uniaxial compression," Advances in Civil Engineering, vol. 2018, Article ID 9818250, 15 pages, 2018.

[7] X. Li, J. Zhou, S. Wang, and B. Liu, "Review and practice of deep mining for solid mineral resources," China Journal Nonferrous Metals, vol. 27, no. 6, pp. 1236-1262, 2017, in Chinese.

[8] M. Tao, H. Zhao, X. Li, J. Ma, K. Du, and X. Xie, "Determination of spalling strength of rock by incident waveform," Geomechanics and Engineering, vol. 12, no. 1, pp. 1-8, 2017.

[9] Y. X. Wang, P. P. Guo, W. X. Ren et al., "Laboratory investigation on strength characteristics of expansive soil treated with jute fiber reinforcement," International Journal of Geomechanics, vol. 17, no. 11, article 04017101, 2017.

[10] Y. Zhao, Y. Wang, W. Wang, W. Wan, and J. Tang, "Modeling of non-linear rheological behavior of hard rock using triaxial rheological experiment," International Journal of Rock Mechanics and Mining Sciences, vol. 93, pp. 66-75, 2017.

[11] Y. Zhao, S. Luo, Y. Wang, W. Wang, L. Zhang, and W. Wan, "Numerical analysis of karst water inrush and a criterion for establishing the width of water-resistant rock pillars," Mine Water and the Environment, vol. 36, no. 4, pp. 508-519, 2017.

[12] D. Blair and A. Minchinton, "On the damage zone surrounding a single blasthole," Fragblast, vol. 1, no. 1, pp. 59-72, 1997.

[13] X. L. Li, D. Y. Li, T. Hu, T. F. Gao, and S. T. Zhang, “Testing method for the weak and broken rock mass blasting vibration in theory and application," Journal of Safety and Environment, vol. 16, no. 2, pp. 148-153, 2016, in Chinese.

[14] H. Lin, P. Cao, and Y. Wang, "Numerical simulation of a layered rock under triaxial compression," International Journal of Rock Mechanics and Mining Sciences, vol. 60, pp. 12-18, 2013.

[15] M. Khandelwal and T. N. Singh, "Prediction of blast-induced ground vibration using artificial neural network," International Journal of Rock Mechanics and Mining Sciences, vol. 46, no. 7, pp. 1214-1222, 2009.

[16] K. W. Liu, H. Hao, and X. B. Li, "Numerical analysis of the stability of abandoned cavities in bench blasting," International Journal of Rock Mechanics and Mining Sciences, vol. 92, pp. 30-39, 2017.

[17] M. Hajihassani, D. J. Armaghani, A. Marto, and E. T. Mohamad, "Ground vibration prediction in quarry blasting through an artificial neural network optimized by imperialist competitive algorithm," Bulletin of Engineering Geology and the Environment, vol. 74, no. 3, pp. 873-886, 2015.

[18] W. Sweldens, "The lifting scheme: a construction of second generation wavelets," SIAM Journal on Mathematical Analysis, vol. 29, no. 2, pp. 511-546, 1998.

[19] G. S. Zhong, L. P. Ao, and K. Zhao, "Influence of explosion parameters on wavelet packet frequency band energy distribution of blast vibration," Journal of Central South University, vol. 19, no. 9, pp. 2674-2680, 2012.

[20] X. L. Li, Z. H. Li, and E. Y. Wang, "Analysis of natural mineral earthquake and blast based on Hilbert-Huang transform (HHT)," Journal of Applied Geophysics, vol. 128, pp. 79-86, 2016.

[21] Y. Wang, P. Guo, F. Dai, X. Li, Y. Zhao, and Y. Liu, "Behaviour and modelling of fiber reinforced clay under triaxial compression by using the combining superposition method with the energy based homogenization technique," International Journal of Geomechanics, vol. 18, no. 12, article 04018172, 2018.

[22] Y. Wang, P. Guo, S. Shan, H. Yuan, and B. Yuan, "Study on strength influence mechanism of fiber-reinforced expansive soil using jute," Geotechnical and Geological Engineering, vol. 34, no. 4, pp. 1079-1088, 2016.

[23] H. Lin, W. Xiong, and Q. Yan, "Modified formula for the tensile strength as obtained by the flattened brazilian disk test," Rock Mechanics and Rock Engineering, vol. 49, no. 4, pp. 1579-1586, 2016.

[24] H. Lin, W. Xiong, and Q. Yan, "Three-dimensional effect of tensile strength in the standard brazilian test considering contact length," Geotechnical Testing Journal, vol. 39, no. 1, article 20140268, 2015.

[25] H. Wang, H. Lin, and P. Cao, "Correlation of UCS rating with schmidt hammer surface hardness for rock mass classification," Rock Mechanics and Rock Engineering, vol. 50, no. 1, pp. 195-203, 2017.

[26] R. Kumar, D. Choudhury, and K. Bhargava, "Determination of blast-induced ground vibration equations for rocks using mechanical and geological properties," Journal of Rock Mechanics and Geotechnical Engineering, vol. 8, no. 3, pp. 341349, 2016.

[27] M. Hajihassani, D. J. Armaghani, M. Monjezi, E. T. Mohamad, and A. Marto, "Blast-induced air and ground vibration prediction: a particle swarm optimization-based artificial neural network approach," Environmental Earth Sciences, vol. 74, no. 4, pp. 2799-2817, 2015.

[28] D. J. Armaghani, M. Hajihassani, M. Monjezi, E. T. Mohamad, A. Marto, and M. R. Moghaddam, "Application of two intelligent systems in predicting environmental impacts of quarry blasting," Arabian Journal of Geosciences, vol. 8, no. 11, pp. 9647-9665, 2015.

[29] X. Z. Shi, X. Y. Qiu, J. Zhou, X. Chen, Y.-Q. Fan, and E.-W. Lu, "Application of Hilbert-Huang transform based delay time identification in optimization of short millisecond blasting," Transactions of Nonferrous Metals Society of China, vol. 26, no. 7, pp. 1965-1974, 2016.

[30] W. B. Lu, P. Li, M. Chen, C. B. Zhou, and D. Q. Shu, "Comparison of vibrations induced by excavation of deepburied cavern and open pit with method of bench blasting," Journal of Central South University of Technology, vol. 18, no. 5, pp. 1709-1718, 2011.

[31] Z. Xu, H. Guo, L. Guo, and X. Liu, "Effects of rock properties on the propagation of blasting vibration," Journal of North China Institute of Science and Technology, vol. 12, no. 4, pp. 25-30, 2015.

[32] G. M. Simangunsong and S. Wahyudi, "Effect of bedding plane on prediction blast-induced ground vibration in open pit coal mines," International Journal of Rock Mechanics and Mining Sciences, vol. 79, pp. 1-8, 2015. 


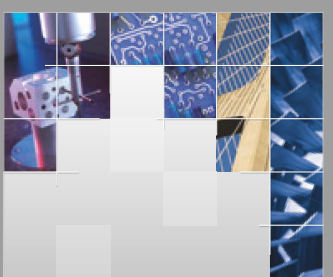

\section{Enfincering}
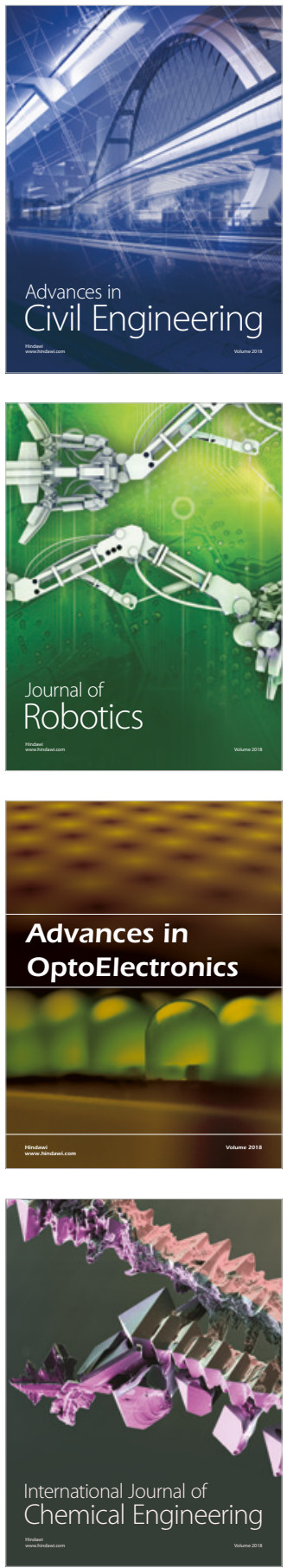

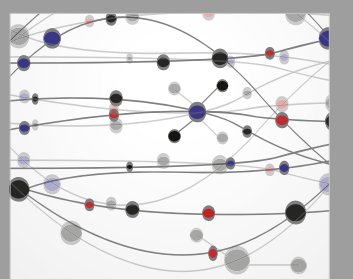

\section{Rotating \\ Machinery}

The Scientific World Journal

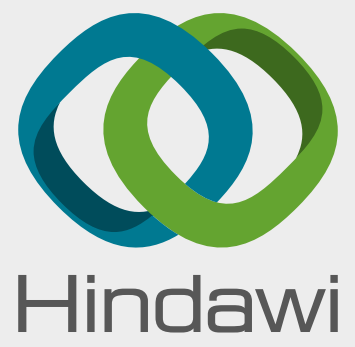

Submit your manuscripts at

www.hindawi.com
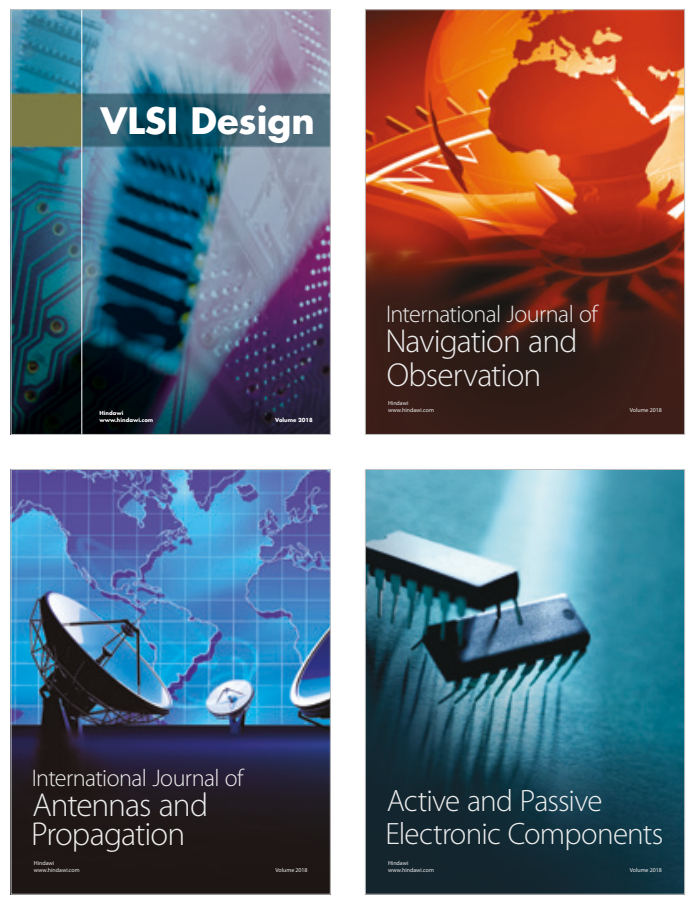
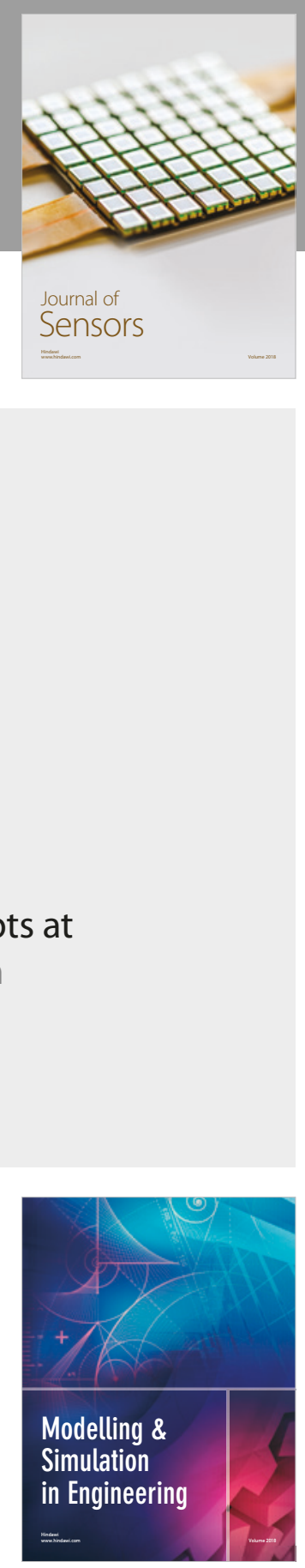

\section{Advances \\ Multimedia}
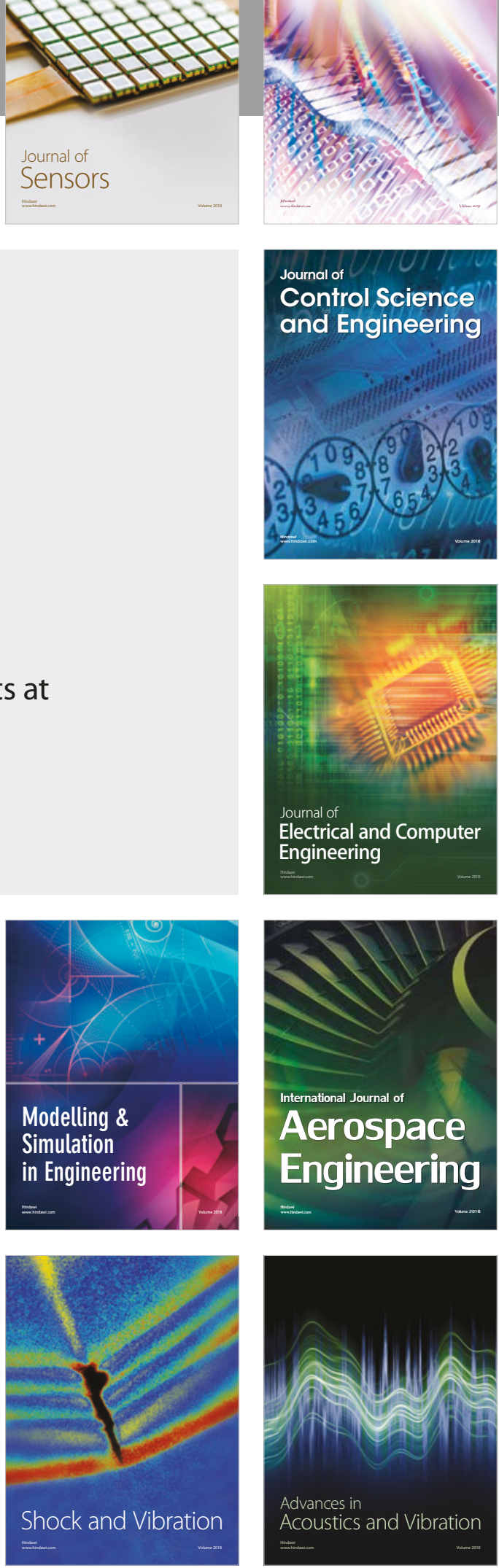